\title{
ВИХРЕВАЯ СТРУКТУРА ВОСТОЧНО-КАМЧАТСКОГО ТЕЧЕНИЯ ПО СПУТНИКОВЫМ НАБАЮАЕНИЯМ
}

\author{
Н.М. Вакульская*, В.А. Аубина, В.В. Плотников \\ Тихоокеанский океанологический институт им. В.И. Ильичева ДВО РАН 690041 , \\ Владивосток, ул. Балтийская, 43, Россия \\ E-mail: vakulskaya@poi.dvo.ru
}

\section{Аннотация}

На основе анализа архива спутниковых мультисенсорных данных исследована динамика ледяного покрова в области Восточно-Камчатского течения. При развитом зимнем муссоне плавучий лёд смещается вдоль побережья Камчатки на юг, трассируя разномасштабные вихри, которые возникают при взаимодействии потока Восточно-Камчатского течения с неоднородностями береговой черты и континентального склона. Средняя скорость дрейфа, рассчитанная по изображениям, полученным в марте 2016 г. в один день с разницей в 110 мин, составила 0,25 м/с, что в два с половиной раза превысило суточное значение. На севере и на юге района значения скорости дрейфа превышали скорости в центральной части. При ослаблении зимнего муссона в поле дрейфующего льда в западной части Берингова моря образуются хорошо выраженные грибовидные структуры, горизонтальные размеры которых могут превышать 200 км. Наряду с известными ранее синоптическими вихревыми образованиями синоптического масштаба спутниковые данные высокого (10-15 м) и среднего (250 м) пространственного разрешения позволили зарегистрировать многочисленные мезомасштабные циклоны диаметром 10-25 км и временем жизни от 1 до 14 суток.

Ключевые слова: Берингово море, ледяной покров, MODIS, Landsat, дрейф льда, грибовидные течения, мезомасштабные вихри. 


\title{
EDDY STRUCTURE OF THE EAST KAMCHATKA CURRENT ACCORDING TO SATELLITE OBSERVATIONS
}

\author{
N.M. Vakulskaya *, V.A. Dubina, V.V. Plotnikov \\ V.I. Il'ichev Pacific Oceanological Institute, FEB RAS, 43 Baltiyskaya St., Vladivostok, \\ 690041, Russia \\ E-mail: vakulskaya@poi.dvo.ru
}

\begin{abstract}
On the basis of the analysis of the satellite multisensor data archive, the dynamics of the ice cover in the region of the East Kamchatka Current is investigated. With the developed winter monsoon, floating ice shifts along the Kamchatka coast to the south, tracing the multi-scale eddies that appear when the East Kamchatka stream interacts with the inhomogeneities of the coastline and the continental slope. The average drift speed calculated from images taken in March 2016 on the same day with a difference of 110 min was $0.25 \mathrm{~m} / \mathrm{s}$, which was two and a half times higher than the daily value. On the north and south of the region, the drift velocity values exceeded the velocities in the central part. With the attenuation of the winter monsoon in the field of drifting ice in the western part of the Bering Sea, well-defined mushroom-like structures are formed, the horizontal dimensions of which can exceed $200 \mathrm{~km}$. Together previously known synoptic eddy formations of a synoptic scale, satellite data of high $(10-15 \mathrm{~m})$ and moderate $(250 \mathrm{~m})$ spatial resolution made it possible to register numerous mesoscale cyclones with a diameter of 10-25 km and a life time of 1 to 14 days.

Keywords: Bering Sea, sea ice cover, MODIS, Landsat, ice drift, mushroom currents, submesoscale eddies.
\end{abstract}

\section{Введение}

Восточно-Камчатское течение - западное пограничное течение субарктического круговорота Тихого океана. Основной поток течения следует примерно от м. Наварин в Беринговом море до центральных Курильских островов. Течение имеет вид узкой струи, ширина которой 25-80 км, максимальные скорости летом достигают 0,40 м/с. Стержень течения совпадает с зоной минимальных температур холодного промежуточного слоя и расположен на расстоянии 100-120 км от берега. На границах течения наблюдаются области повышенных горизонтальных градиентов термохалинных характеристик [3-4]. 
Восточное побережье п-ова Камчатка представляет собой пять крупных заливов, в которых в разные сезоны на спутниковых изображениях регулярно регистрируются синоптические вихри [2-6]. Вихри прослеживаются в полях температуры и цвета воды, дрейфующего льда и на картах динамической топографии, построенных по спутниковым альтиметрическим измерениям. Подавляющее большинство вихрей являются антициклонами, имеют спиральную структуру и холодные ядра. Их размеры составляют 70-150 км и они смещаются в южном и юго-западном направлении со скоростями 1-10 км/сутки [3-4]. Считается, что причиной образования вихрей является влияние на Восточно-Камчатское течение неоднородностей рельефа дна и береговой черты.

Для более детального исследования вихревой структуры в области Восточно-Камчатского течения были использованы изображения ледяного покрова, полученные по съёмкам спектрорадиометров MODIS co спутников Terra и Aqua. Дополнительно привлекались снимки со спутников серий Landsat и Sentinel-1/2 (пространственное разрешение соответственно 15 и 10 м).

\section{Данные и методы}

Данные MODIS отбирались и загружались через портал Rapid Response Project http://rapidfire.sci.gsfc.nasa.gov/ центра космических полетов им. Годдарда (Goddard Space Flight Center - GSFC) в NASA. Для анализа создавались изображения в истинном цвете с разрешением 250 м, которые комбинировались из 1-го (длина волны $\lambda=0,645$ мкм, разрешение $250 \mathrm{~m}), 4$-го $(\lambda=0,555$ мкм, разрешение 500 м) и 3-го ( $\lambda=0,469$ мкм, разрешение 500 м) спектральных каналов.

Скорость и направление дрейфа льда рассчитывались методом маркеров по двум изображениям MODIS на временных интервалах 110 мин и примерно одни сутки, а также по совмещённым панхроматическим снимкам Landsat и радиолокационным со спутников Sentinel-1A/B (временные интервалы 4-24 ч). Ошибка коллокации пар изображений не превышала одного пикселя, поэтому точность расчётов оценивается не хуже $0,04 \mathrm{~m} / \mathrm{c}$.

Дрейф льда определяется суммарным действием напряжения ветра, течений и силой Кориолиса. С увеличением периода времени, за 
который рассчитывается смещение льда, увеличивается роль непериодических течений в суммарном дрейфе, а роль ветрового напряжения уменьшается. Сравнение дрейфа льда, полученного на разных временных интервалах, позволяет оценить и сопоставить вклад различных сил на результирующее движение льда [7]. На интервале 110 мин при незначительных скоростях ветрового дрейфа и непериодических течений основной вклад в динамику ледяного покрова вносят приливы, поэтому скорость приливного дрейфа можно использовать как нижнюю оценку скорости приливных течений [1]. Для безоблачного периода с 9 по 15 марта 2016 г. было рассчитано 340 векторов дрейфа на интервале 110 мин и 614 на интервале 23-25 часов, по которым построено 10 карт.

\section{Основные результаты}

Анализ спутниковых изображений ледяного покрова у восточного побережья Камчатки показывает наличие двух основных режимов дрейфа льда. При развитом зимнем муссоне плавучий лёд прижимается северо-западными ветрами к берегу и смещается на юг, при этом лёд трассирует разномасштабные вихри, которые возникают при взаимодействии потока Восточно-Камчатского течения с неоднородностями береговой черты и континентального склона. На рис. 1 представлено изображение в видимом диапазоне электромагнитного спектра, полученное 12 марта 2016 г. спектрорадиометром MODIS co спутника Aqua. Стрелками показаны вектора дрейфа льда, рассчитанные на временном интервале 110 мин. На врезках показаны увеличенные фрагменты изображения размером 87,5х87,5 км. Лёд дрейфовал вплотную к берегу в полосе шириной 40-150 км. Средняя скорость дрейфа, рассчитанная по изображениям, полученным в один день с разницей в 110 мин, составила $0,25 \mathrm{~m} / \mathrm{c}$, что в два с половиной раза превысило суточное значение. На севере и на юге района значения скорости дрейфа превышали скорости в центральной части (в заливах Карагинский и Озерной). На фоне генерального дрейфа на юго-запад в ледяном покрове наблюдались вихри разного знака. Причём, антициклоны синоптического масштаба отмечались только в Авачинском заливе и около юго-восточной оконечности полуострова Кроноцкий (врезка 2 на рис.1). В остальных заливах регистрировались нестаци- 
онарные спиральные циклоны диаметром 15-25 км (врезки 1, 3 на рис.1). Орбитальные скорости в них достигали $0,20-0,30$ м/с. Эти мезомасштабные образования наблюдались на протяжении 3-4 суток, меняя свои очертания и смещаясь на юг.

В работе [2] авторы как наиболее вероятный источник энергии для возникновения грибовидных течений рассматривают гидроди-

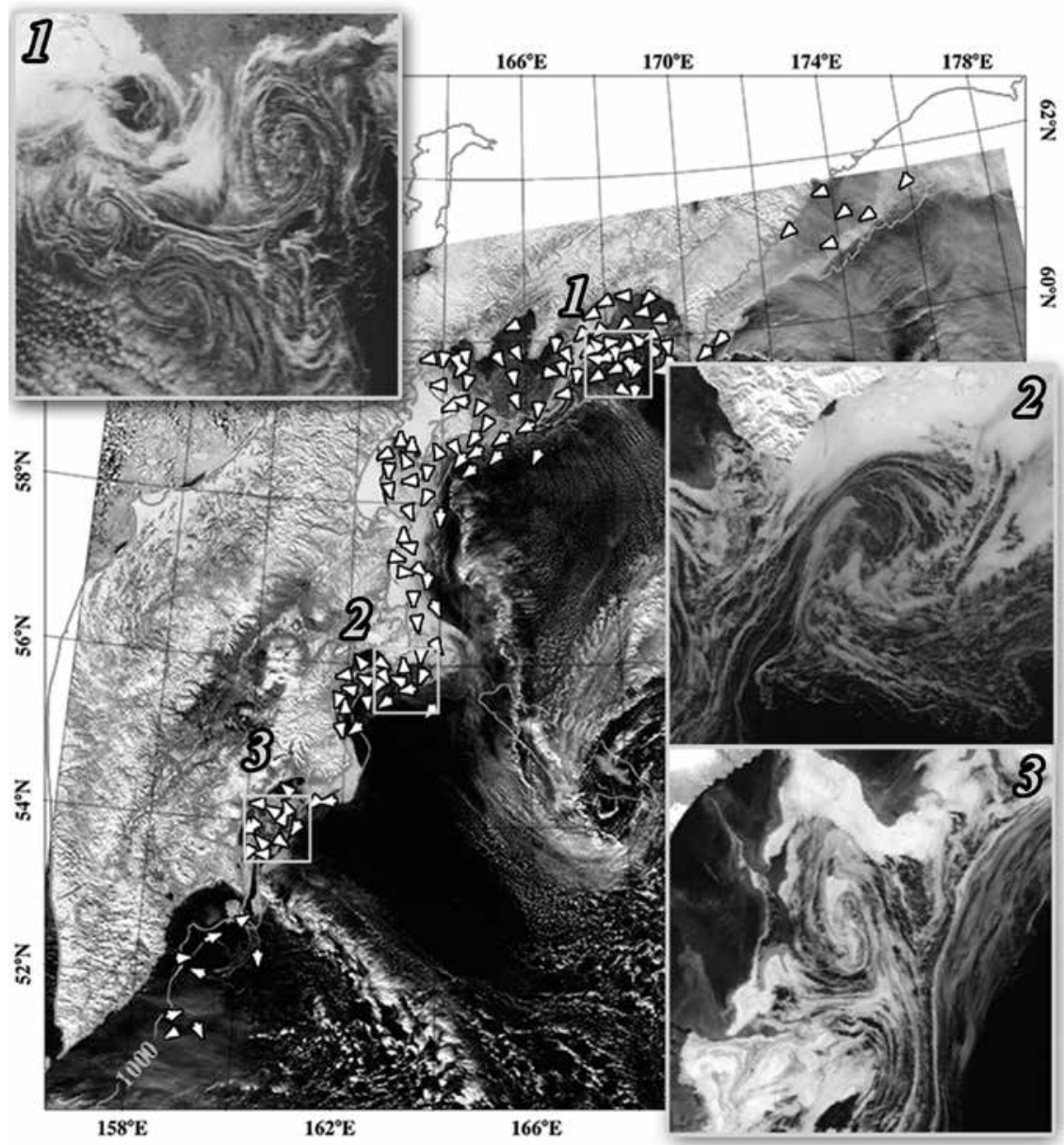

Рис. 1. Изображение в видимом диапазоне электромагнитного спектра, полученное 12 марта 2016 г. спектрорадиометром MODIS со спутника Aqua. Стрелками показаны вектора дрейфа льда, рассчитанные на временном интервале 110 мин. На врезках показаны увеличенные фрагменты изображения размером 87,5х87,5 км 
намическую неустойчивость движений синоптического масштаба и приводят примеры вихревых структур в поле разрушающегося льда в юго-западной части Охотского моря. Похожая картина периодически наблюдается в апреле в западной части Берингова моря. При ослаблении зимнего муссона лёд отдельными полосами шириной

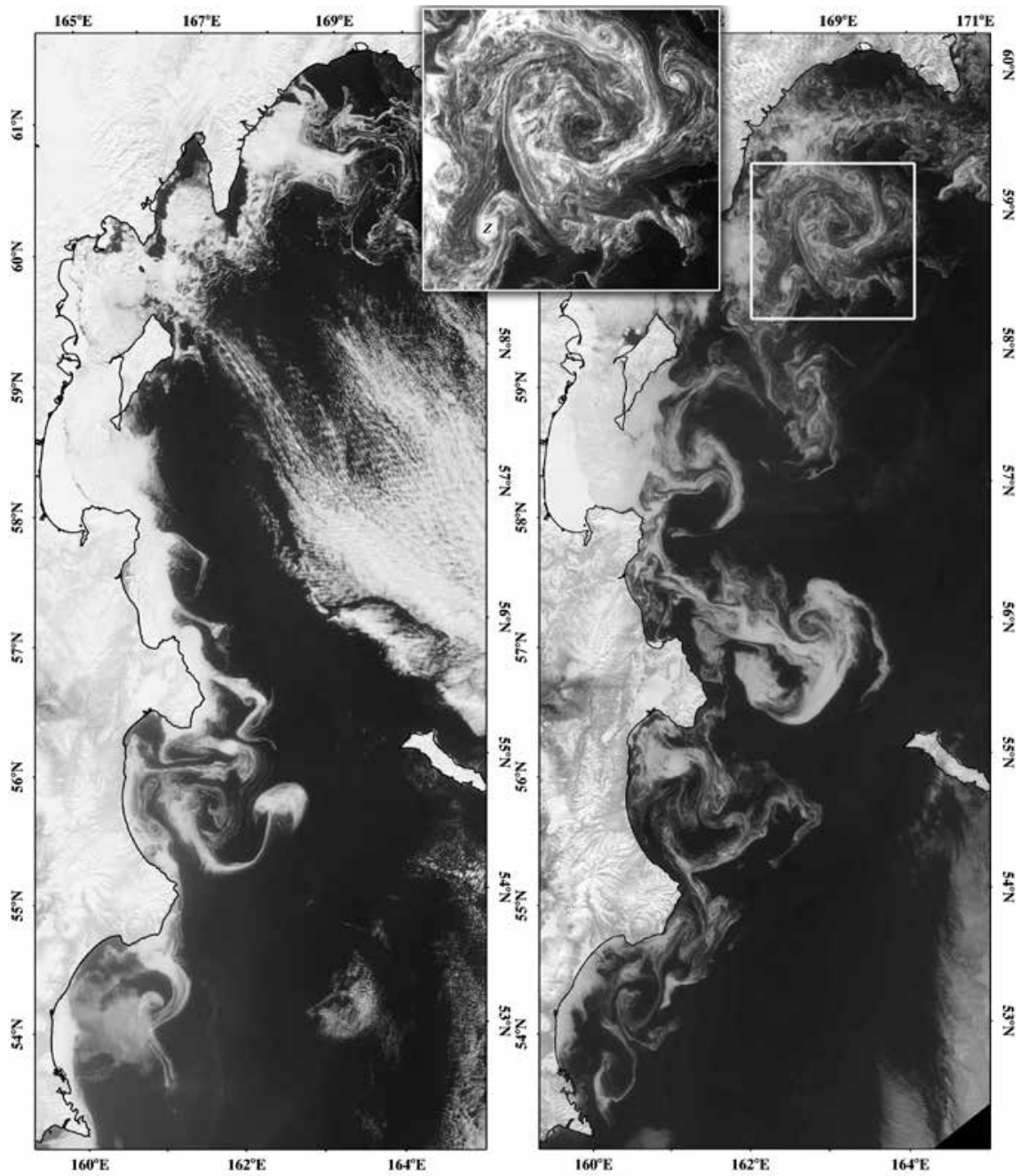

Рис. 2 Ледяной покров на изображениях, полученных спектрорадиометром MODIS со спутника Aqua 3 апреля 2016 г. (слева) и 17 апреля 2012 г. (справа). На врезке увеличенный фрагмент, границы которого показаны белым прямоугольником 
5-25 км начинает дрейфовать от берега, образуя хорошо выраженные грибовидные структуры. Подобная картина наблюдалась, например, 3 апреля 2016 г. (рис. 2, слева) и 17 апреля 2012 г. (рис. 2, справа). Максимальные размеры зарегистрированы у грибовидной структуры в районе Камчатского пролива (рис. 2, справа): длина струйной части превышала 200 км, а ширина вихревой - 150 км. Образование и развитие грибовидных структур сопровождалось мезомасштабным циклогенезом (рис. 2, врезка).

Большинство циклонических вихрей были нестационарные, но циклон с диаметром ядра 10 км, обозначенный на врезке буквой $Z$, прослеживался на спутниковых изображениях две недели.

\section{Заключение}

Вдоль всего восточного побережья п-ова Камчатка с середины 1970-х годов по данным гидрологических съемок и дистанционных наблюдений регистрируются синоптические вихревые образований спиральной формы с горизонтальными размерами, достигающими 100-150 км $[4,6,8]$. Известно, что вихри синоптического масштаба могут сопровождаться нестационарными мезомасштабными явлениями - струями, вихрями, грибовидными структурами. Не исключением в этом аспекте является область Восточно-Камчатского течения, где спутниковые данные высокого (10-15 м) и среднего (250 м) пространственного разрешения позволили зарегистрировать многочисленные мезомасштабные циклоны диаметром 10-25 км. Большинство этих вихрей наблюдаются на спутниковых снимках не более 1-2 суток, но наряду с ними зарегистрирован циклон диаметром 10 км и временем жизни не менее двух недель. При развитом зимнем муссоне плавучий лёд, трассируя разномасштабные вихри, смещается вдоль Камчатки на юг со скоростями $\sim 0,1 \mathrm{~m} / \mathrm{c}$. При ослаблении северо-западных ветров в западной части Берингова моря в поле дрейфующего льда образуются хорошо выраженные грибовидные структуры, горизонтальные размеры которых достигают 200 км и более. 


\section{^итература}

1. Жабин И.А., Лукьянова Н.Б., Дубина В.А. Структура и динамика вод морской акватории Национального парка «Шантарские острова» (Охотское море) по данным спутниковых наблюдений // Исследование Земли из космоса. 2018. № 5. С. 3-14.

2. Гинзбург А.И., Фёдоров К.Н. Некоторые закономерности развития грибовидных течений в океане, выявленные путём анализа спутниковых изображений // Исследование Земли из космоса. 1984. № 6. С. 3-13.

3. Радиолокация поверхности Земли из космоса / Под ред. Митника Л.М., Викторова С.В. Ленинград: Гидрометеоиздат. 1990. 200 с.

4. Храпченков Ф.Ф. Гидрологическая структура и распределение энергии вихрей Камчатского течения // Метеорология и гидрология. 1989. № 1. С. 65-71.

5. Храпченков Ф.Ф. Исследование вихрей у побережья Камчатки летом 1985 г. // Океанология. 1987. Т. 27. Вып. 3. С. 391-396.

6. [Электронный ресурс] Ростов И.Д., Рудых Н.И., Дмитриева Е.В., Ростов В.И., Храпченков Ф.Ф., Рогачев К.А., Новотрясов В.В., Мороз В.В., Дубина В.А., Микрюков А.В., Попов О.Е. Атлас гидрофизических характеристик района юго-восточной части полуострова Камчатка. 2004. URL: http://pacificinfo.ru/data/cdrom/6/ $\mathrm{htm} / 3 \_3 \_$_htm

7. Plotnikov V. V., Dubina V. A., Vakul'skaya N. M. Estimation of Sea Ice Drift on the Sea of Okhotsk Shelves Based on Satellite Data // Russian Meteorology and Hydrology. 2018. Vol. 43. No. 12. P. 871-39.

8. Solomon H., Ahlnäs K. Eddies in the Kamchatka Current // Deep Sea Research. 1978. Vol. 25. No. 4. P. 403-410.

\section{References}

1. Zhabin I.A., Lukyanova N.B., Dubina V.A. Struktura i dinamika vod morskoy akvatorii Natsionalnogo parka "Shantarskiye ostrova" (Okhotskoye more) po dannym sputnikovykh nablyudeniy) [Water structure and dynamics in the Shantar Islands National Park aquatory (Sea of Okhotsk) according to satellite observations]. Issledovaniye Zemli iz kosmosa. 2018. No. 5. P. 3-14. (in Russian).

2. Ginzburg A.I., Fedorov K.N. Nekotoryye zakonomernosti razvitiya gribovidnykh techeniy v okeane, vyyavlennyye putem analiza sputnikovykh izobrazheniy [Some patterns of the development of mushroom currents in the ocean, revealed ways of analyzing satellite images]. Issledovaniye Zemli iz kosmosa. 1984. No. 6. P. 3-13. (in Russian).

3. Radiolokatsiya poverkhnosti Zemli iz kosmosa [Earth surface radar from space]. Pod red. Mitnika L.M., Viktorova S.V. Leningrad: Gidrometeoizdat. 1990. 200 p. (in Russian).

4. Khrapchenkov F.F. Gidrologicheskaya struktura i raspredeleniye energii vikhrey Kamchatskogo techeniya [Hydrologic structure and the distribution of energy of eddies in the Kamchatka current]. Meteorologiya i gidrologiya [Russian Meteorology and Hydrology]. 1989. No. 1. P. 65-71. (in Russian) 
5. Khrapchenkov F.F. Issledovaniye vikhrey u poberezhya Kamchatki letom 1985 g. [Field study of eddies near the Kamchatka coast in the summer of 1985]. Okeanologiya [Oceanology]. 1987. Vol. 27. No. 3. P. 391-396. (in Russian).

6. [Elektronnyy resurc] Rostov I.D., Rudykh N.I., Dmitriyeva E.V., Rostov V.I., Khrapchenkov F.F., Rogachev K.A., Novotryasov V.V., Moroz V.V., Dubina V.A., Mikryukov A.V., Popov O.E. Atlas gidrofizicheskikh kharakteristik rayona yugo-vostochnoy chasti poluostrova Kamchatka Oceanographic atlas for the coastal ocean off the northeastern Kamchatka peninsula. [Oceanographic atlas for the coastal ocean off the northeastern Kamchatka peninsula]. 2004. (in Russian). URL: http://pacificinfo.ru/data/cdrom/6/ $\mathrm{htm} / 3 \_3 \_0 . \mathrm{htm}$

7. Plotnikov V. V., Dubina V. A., Vakul'skaya N. M. Estimation of Sea Ice Drift on the Sea of Okhotsk Shelves Based on Satellite Data. Russian Meteorology and Hydrology. 2018. Vol. 43. No. 12. P. 871-39.

8. Solomon H., Ahlnäs K. Eddies in the Kamchatka Current. Deep Sea Research. 1978. Vol. 25. No. 4. P. 403-410. 